\section{CHARGE-TRANSFER COMPLEXES}

Organic Charge-Transfer Complexes

By R. Foster. (Organic Chemistry: A Series of Monographs.) Pp. xii +470 . (Academic Press: London and New York, October 1969.) 160s; $\$ 22.50$.

THE reversible interaction between molecules to form complexes has been known for more than 100 years; in the past 20 years, a great deal of work has appeared on this topic, largely the result of applying spectroscopic techniques to study of these complexes. In the preface to this book, Dr Foster states that at least four hundred relevant papers have appeared during the past year. The author has made important contributions to this subject and he has written a useful summary of the properties and reactions of charge-transfer complexes.

A valuable feature of the book is the critical account of the various methods used for determining equilibrium constants for complex formation, especially the one using absorption spectroscopy, and various ways of handling the data are discussed. Nuclear magnetic resonance studies have recently been used to yield values of the equilibrium constants and this method appears to be of great use. It has recently been shown, however (M. J. Foreman, R. Foster and D. R. Twiselton, Chem. Commun., 1318; 1969), that the values of $\mathrm{K}$ obtained may depend on which particular nucleus is being observed and the method must be applied with care. There is also a useful summary of the complexes whose structures have been determined by $\mathrm{X}$-ray crystallography. Foster also draws attention to the difficulties of comparing the complexing ability of different donors and acceptors. No attempt has been made to give a complete list of all complexes; rather, some ten woll chosen examples aro described in detail.

Charge-transfer complexes are important in biological systems, but the evidence for complexing is sometimes tenuous, almost any appearance of colour being ascribed to complex formation. The critical assessment of the evidence for complexes in biological systems is most welcome.

The book is up to date, well produced, has many useful tables, and may be highly recommended. Unfortunately, the index is a little lacking in detail: for instance, under 1,3,5-trinitrobenzene, sixty-four pago referenecs are given with no further information.

A. S. BAtLey

\section{CONCEPTION AND CONTRACEPTION}

Birth Control

Now and Tomorrow. By Clive Wood. Pp. xii +211. (Peter Davies: London, November 1969.) $36 s$.

\section{Conception, Birth and Contraception}

A Visual Presentation. By Robert J. Demarest and John J. Sciarra. Pp. 129. (Hodder and Stoughton: London, October 1969.) $42 s$.

Ir is always useful to disseminate scientific knowledge to as wide an audience as possible, and in the case of human reproduction and birth control thore is an obligation to undertake this particular task. The most suitable interpreters of sciontific knowledge for a wide audience are usually professional scientists, and the authors of both these books are engaged in research work or clinical practice.

Birth Control: Now and Tomorrow is a carefully written book which manages to explain complicated biological medical topies in non-technical language but without undue simplification. All methods of birth control are dealt with, an excellent review of possible future methods is given and some useful insights into the past history of the neglected topic of contraception are provided. Prob- ably the most valuable part of the book is an excellent summary of the topic of oral contraceptives which includes a very honest account of proven and possible hazards and side effects associated with this form of family planning. At a time when the Pill is the subject of a great deal of publicity, it is interesting that it should have been a biologist rather than a clinician who has provided a balanced and useful account of this important topic. A good, brief but realistic account of the problems associated with oral contraceptive usage in developing countries is to be particularly commended.

Conception, Birth and Contraception is an attempt to provide visual presentation of the biological and medical aspects of these subjects combined with a brief, bland text. It is certainly true to say that the information contained is presented in such a way that it could not upset any teenage girl, but it may also be that it would add relatively little to her knowledge. The book is perhaps unreasonable in its unnecessary defence of circumcision and unrealistic in its omission of any account of induced abortion, which remains a very important part of the total pattern of fertility control in the devoloped world.

Books like these are going to become increasingly important in the coming decade; they require a considerable investment of scientific skill and it is to be hoped that their aims and consequences will be evaluated in a constructive way by other scientists. There are obvious difficulties in dealing with topics associated with human reproduction. Wood has overcome certain of these by an ability to spot the comic in sexual behaviour while retaining compassion for those who are forcod to use inadequate or even unpleasant methods of birth control. Demarest and Sciarra have adopted a colder, more clinical, approach which may prove more acceptable to community leaders but is perhaps less useful to the lay public that needs responsible and constructive information. D. M. Potтs

\section{THE PILL, UP TO 1967}

\section{Hormonal Contraception}

By Jürgen Haller. Translated from the second German edition by Herbert Gottfried. Pp. 288. (Geron-X: Los Altos, California, 1969.) \$12.

THE widespread accoptance and use of steroid oral contracoptives in Western countries have produced a mass of medical and sciontific literature. There is no doubt that there is a definite need for a book in English that critically ovaluates this literature and sets out an up to date summary of the complex physiology, biochemistry and pathology in a clinical context. Unfortunately, this is not that book.

To begin with, this is a translation of a book that was clearly completed in 1967 , for no publications after that date are cited. Second, the translation from the German is poor. The text is full of phrases such as "certainty for successful uso", meaning "reliability"; there are also numerous trivial typographical mistakes.

For some strange reason, the figures are taken directly from the German edition and all words included in the figures are still in the German language. A key is provided, but often on another page. Errors in the German figures have not been corrected. For example, two of the three structural formulae in Fig. 19, page 54, are quite incorrect, yet the errors are clearly only carelessness. In some figures "norethisteron" is translated as the American "norethin. drono", but the text is schizophrenic and often refers to "norethisterone". Somctimes both words are intermixed on the same page (for example, page 5) without making it clear that they refer to the same compound.

The book consists of eight chapters: ovulation, inhibition of ovulation, clinical use of ovulation-suppressing 